\title{
Thoughts on the Future of Bibliographical Analysis
}

\author{
David L. Vander Meulen*
}

I have been asked to talk today about the future of analytical bibliography in the computer age. Almost every noun in that mandate poses a challenge. First of all, it would seem far easier to speak instead about the past, and contemplating the past probably would also be more productive for understanding both the present and the future. This is the wise approach that David Foxon incorporated in a talk from whose title I borrow, Thoughts on the History and Future of

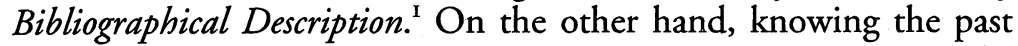
is extremely difficult too, though one of the points I want to make today is that bibliographical analysis gives us a means of tackling that problem.

Analytical bibliography is the next difficult term. It is a familiar one and indeed appears in the first objective of the constitution of the Bibliographical Society of Canada, whose goal is "To promote the study and practice of bibliography: enumerative, historical, descriptive, analytical, and textual." 2 This Society has in fact been the beneficiary of a full lecture on that taxonomy, for in 1971 Fredson Bowers addressed its Colloquium on Nineteenth-Century Canadian Bibliography at Massey College on the topic "Four Faces of Bibliography."3 Noting that these areas are, as he said, "in fact, interdependent, and [that]

* David L. Vander Meulen is Professor of English at the University of Virginia and Editor of Studies in Bibliography. His current research focuses on the bibliography of Alexander Pope and on the work of the twentieth-century American book designer Warren Chappell.

I David F. Foxon, Thoughts on the History and Future of Bibliographical Description (Los Angeles: School of Library Service, University of California; Berkeley: School of Librarianship, University of California, 1970).

2 The constitution may conveniently be found on the Society's Web site: http:// www.library.utoronto.ca/bsc/constitutioneng.html or http://www.library. utoronto.ca/bsc/constitutionfre.html.

3 Fredson Bowers, "Four Faces of Bibliography," Papers of the Bibliographical Society of Canada Io (1971): 33-45; reprinted in Bowers's Essays in Bibliography, Text, and Editing (Charlottesville, VA: University Press of Virginia for the Bibliographical Society of the University of Virginia, 1975), 94-108, from which the following quotations are drawn. 
each merges - sometimes almost imperceptibly - into the other," he also emphasized the need for scholars to recognize the distinctiveness of these approaches and, when working in them, "always [to] be conscious of ... [one's] place in the whole spectrum" (94-95). Although "Accurate and meaningful description cannot be written unless the books have first been subjected to analytical examination" (95), analysis is not always directed at preparing a record of physical features. Ultimately analytical bibliography seeks to use physical details as a way of determining something about the history of the book, usually its manufacturing history. Just as bibliographical description could have a number of purposes (among them, to serve as a guide to collecting, a source book for pursuing various historical interests, or a basis for tracing the textual history of a work), so could the findings of bibliographical analysis be directed to different ends. In Bowers's own case, a logical but not exclusive application of insights into the manufacturing history of a book was of course to the study of the text of that book, and then in turn to its editing.

Some examples of analytical bibliography in operation might remind us what it looks like. One of the most famous applications is that of Allan H. Stevenson, who traced with precision the states of deteriorating watermarks in the so-called "Constance Missal" and in order to provide a date for this book (which some believed to be the first European book printed from moveable type) correlated those marks with examples in other books whose dates were known. ${ }^{4}$ It is what Carl Spadoni does when, after describing the physical components of an edition of Stephen Leacock's Sunshine Sketches of a Little Town, he determines that those features "would suggest that ... [the book] is simply a reprint from The Bodley Head rather than an issue designed specifically for Gundy."5 It is what Patricia Lockhart Fleming does when she concludes that the typography of a New Brunswick publication of I8I4 "show[s] that the volume was printed at Ann Mott's shop." It is what Jo-Ann E. McEachern does when she uses the evidence of signatures and press variants to establish the order of the duodecimo and octavo formats of the first edition of Rousseau's Emile and when she employs differences in

4 Stevenson's study of the missal culminated in his book, The Problem of the Missale Speciale (London: Bibliographical Society, 1967).

5 Carl Spadoni, A Bibliography of Stephen Leacock (Toronto: ECW Press, 1998), II8, entry Arra.3.

6 Patricia Lockhart Fleming, Atlantic Canadian Imprints, I80I-I820: A Bibliography (Toronto: University of Toronto Press, 1991), 27, entry NB52. 
compositorial practices and in type-faces to distinguish the printers of its various sections. ${ }^{7}$ And it is what Randall McLeod does when he examines offsetting in copies of Richard Bentley's $A$ Dissertation upon the Epistles of Phalaris and employs it to explain apparent anomalies in the book. ${ }^{8}$

The third term that raises questions is computer age or digital age. Curiously, generalizations on this pattern continue to proliferate even in an age where the designation of "ages" has become suspect. In literary study, for instance, one seldom hears any more of the Augustan Age or of the Age of Johnson. Several reasons exist for that wariness. One is that even when a new feature or activity arises, it often supplements rather than supplants existing ones, which then continue along with the new. In his devastating analysis of the confusing use of the term print culture, Harold Love has pointed out this kind of situation: "we should," he says, "cease to see it [that is, print] as somehow isolated from the complementary and often actively co-operating media of the oral, the scribal and the physically performative." Moreover, even when certain characteristics have become prominent, they seldom are as exclusive as the label suggests. The surge in computer use beginning in the 1980s roughly corresponded with the adoption of microwave ovens. In 1983, 12.5\% of Canadian households had such an appliance for cooking; ${ }^{\text {IO }}$ by 2003 , the rate had jumped to $95 \%$. ${ }^{\text {II }}$ To call ours the Microwave Age, however, would be to falsify its overall character (and all the more so if the designation implied that other ovens are obsolete). Labels tend to prejudice the discussion toward the framer's interpretation of events, a phenomenon captured for me in the phrase

7 Jo-Ann E. McEachern, Bibliography of the Writings of Jean Jacques Rousseau to I80o, vol. 2, Émile, ou De l'éducation (Oxford: Voltaire Foundation, Taylor Institution, 1989), 17, 25.

8 Randall McLeod, "Remote Offsetting in Richard Bentley's A Dissertation upon the Epistles of Phalaris, London, 1699 " (paper presented at the Society for Textual Scholarship: I4th Biennial International Interdisciplinary Conference, New York, Is March 2007).

9 Harold Love, "Early Modern Print Culture: Assessing the Models," Parergon 20, no. I (2003): 45-64 (p. 64).

Io .Canadian Market Data Available," Business America 7, no. 22 (29 October 1984): 40, citing the report Household Facilities and Equipment - 1984 from Statistics Canada.

II Natural Resources Canada, Office of Energy Efficiency, 2003 Survey of Household Energy Use (SHEU) - Summary Report (Ottawa: Natural Resources Canada, Office of Energy Efficiency, 2006), 7, chart 8, also available online at http://www. oee.nrcan.gc.ca/Publications/statistics/sheu-summary/trends.cfm?attr (accessed I8 June 2007). 
of a literary critic teleologically describing the critical standards of the seventeenth-century writer Sir William Temple, who, said the scholar, "anticipates ... the pre-Romantics." ${ }^{2}$

It is with those apprehensions that I stand before you. My plan is not to trace the history of analytical bibliography, for that has been done before by G. Thomas Tanselle in his 1997 Sandars Lectures ${ }^{\mathrm{I} 3}$ and will shortly be done by Richard Landon at our present conference. Nor will I assume a mantle of infallibility and purport to tell you what the future holds. What I hope to do, however, is to suggest some opportunities that the current environment provides.

The first of those opportunities is the chance to analyze books in what might be considered conventional ways. The possibility is enticing first of all because of the sheer quantity of books available. Of the quarter million or so publications that the English Short Title Catalogue (ESTC) lists for the eighteenth century, to take a time I am especially interested in, only those by a handful of authors and printers have received systematic bibliographical description. The number of those books in turn whose features have then been examined for evidence of their manufacturing history constitutes a minuscule percentage of the items that exist from the period. The same holds true for publications of any era, with both the raw numbers and the percentages shrinking to oblivion as the record comes nearer to the present. The opportunities provided by that dearth are further extended by the advent of electronic databases such as the ESTC, through which the identification of copies for examination has become all the easier.

The breadth of possibilities can also be glimpsed if one looks beyond the kind of books most often accorded such treatment, those with literary interest. When Robin Alston addressed the previous convocation of this group in 1992 and ventured that a 1983 book by Ithiel de Sola Pool entitled Technologies of Freedom (Cambridge: Belknap Press of Harvard University Press, 1983) might have been the first one produced from an author's floppy disks, he said, "Now I don't suppose that anyone is ever going to subject Pool's book to bibliographical scrutiny, so you may well ask why does anyone

I2 Robert C. Steensma, Sir William Temple (New York: Twayne Publishers, 1970), 95 .

I3 G. Thomas Tanselle, "Bibliographical Analysis: An Historical Introduction" (Sandars Lectures, Cambridge University, I2, I4, 16 May 1997). Tanselle currently is preparing the lectures for publication. 
care how it was produced. But what," he adds, "of the Cambridge edition of Lawrence?" He continued with a sentence that was not included in the publication of his talk in the centenary volume of the Bibliographical Society in London: "Here, at least, we have a major twentieth century writer - the sort that even Charlottesville or Austin take some interest in." ${ }^{\text {"4 }}$ Alston is quite right in suggesting that the books of notable literary authors have received far more bibliographical attention than those of other writers, and he makes the crucial points that any book is susceptible to bibliographical analysis and that all books can yield insight both into their own history and into the broader contexts in which they have existed. He happens to be wrong, both historically and predictively, about the incidental matter of Charlottesville's interest, and the application of bibliographical analysis to all kinds of books is exactly what I want to encourage.

The potential for new analysis also arises from the features of typesetting and presswork that are available for study. Even when bibliographical examination becomes relatively detailed and identifies type fonts or names watermark designs, it seldom presses those insights to illuminate the details of printing-house practice. And even less commonly does it analyze activities of typesetting or presswork that were not meant to leave evidence of their routines but whose effects are nonetheless sometimes present and visible-the pattern of recurrent running-titles and their indication of skeleton formes, the textures that reveal which side of a sheet was printed first, the holes left by the pins holding the sheet on the tympan of the press, the sequence of press figures, the variations created by stop-press corrections, the progressive deterioration of pieces of type and ornaments, or the presence of bearers that accidentally leave blind impressions on the sheets. Each of these features offers a productive approach for understanding the activities of the people who produced these books a year or a century or half a millennium ago.

I4 Robin Alston, "Bibliography in the Computer Age," Third National Conference on the State of Canadian Bibliography: Achievements, Challenges and Opportunities (Toronto: Bibliographical Society of Canada, in cooperation with the Association for Canadian Studies, 1994), I8I-92 (p. 185). "The text of this essay is substantially that of the Presidential Address delivered to the Bibliographical Society in 1990 and printed in The Book Encompassed: Studies in Twentieth-Century Bibliography, ed. Peter Davison (Cambridge: Cambridge University Press, 1992), 276-89" (p. 190). Except where noted, subsequent quotations from Alston's essay are drawn from the 1994 publication. 
Another largely undeveloped way of mining the physical characteristics of books is to analyze their design features for the meanings that their creators and their users attributed to them. Aspects of this exciting approach to objects have become widely known in recent decades by D. F. McKenzie's phrase the "sociology of texts," but to a large extent the analysis it has propelled has remained impressionistic. In his Sandars Lectures Tanselle points out how, when informed by rigorous historical methodology, the study of design features might appropriately be considered a form of analytical bibliography, for it too seeks to learn something about the history of the books from their physical features. Such examination can include the physiological effects that various elements (such as type font, or line length) have had on readers, the cultural associations that the elements both evoke and reflect at points in their life, or the ways in which the components create meaning. "The voices we hear through the marks printed in books," he says, "are not just those of authors, but of designers, printers, and publishers as well, and of the cultures and politics they inherited and engaged in. To appreciate this story properly we must finally combine the psychological, cultural, and aesthetic analyses of design features with the results of the study of manufacturing clues. This grand project is still in its infancy." Is

If such study is to take place, the objects of that study will have to exist. They will also need to be present in multiple copies, not simply to enable widespread access but also because both comparing features across copies and reasoning inductively from multiple exemplars are at the heart of the enterprise. The future of bibliographical analysis, therefore, is tightly bound with the policies of collectors, especially institutional ones. The British Library's discarding of 60,000 volumes of foreign newspapers in 1999 and 2000 was a reminder of the fragile status of printed objects even in what might seem to be the most stable settings. That episode also brought to light various attitudes that underlie and underscore the threat to the bibliographer's special objects of inquiry. At a London conference in $200 \mathrm{I}$ in the wake of this dispersal, the director of a research library argued that only samples needed to be saved ("to let future scholars know what the artefact looked like at various points in time") and that the rest "might be reformatted in microfilm" - as if there were no difference between microfilm and print, other than the space they occupy. Finding

Is The quotation comes from the conclusion of Tanselle's third (and final) lecture, "Analysis of Design Features." 
solace in the remark by an historian that "'there is far too much being saved for twentieth-century history," this librarian also observed that "Scholars cannot possibly study all the material available even on a relatively discrete research topic."

In a moment I will suggest how computers can be a boon to bibliographical analysis, but in the present context I should point out how they also have the capacity to work against such scholarship. As Terry Belanger predicted in the centenary volume of the Bibliographical Society, "The retrospective conversion of cataloguing records for old books into machine-readable form will continue. The records thus produced, it will shortly be discovered, are going to be useful in determining what gets used: materials that don't get used are going to be particularly likely candidates for deaccession." ${ }^{17}$ But to the bibliographer, popularity and significance are not synonymous. With regret, I can testify that Belanger's 1992 prophecy is being fulfilled. Moreover, in tracking the frequency with which items have been checked out of the library, the same computer systems can be used to decide which ones to accept in the first place. At my own university a couple of years ago, computer records revealed that the bibliographical publication Long Room from Trinity College, Dublin, fell short in the number of times that bound volumes were checked out of the building from the open stacks, and despite the cost of only eleven euros per annum its subscription was discontinued. The same library employs a "management tool" that provides criteria, or what it calls "metrics," to assess the performance of institutional functions. One of them, Metric L.3.a, "Expenditures for electronic materials," states that "partial success" will consist of the library ranking "in the top third of all ... [Association of Research Libraries members] in percentage of collections dollars expended on electronic materials," while "complete success" comes if the library ranks in the top quarter. ${ }^{18}$ Librarians who buy books (and thereby lower that percentage) do so to the detriment of their annual performance rating. One result is that printed books that otherwise would have

I6 Karin Wittenborg, "A Librarian Looks at Preservation," in Do We Want to Keep Our Newspapers?, ed. David McKitterick (London: Office of Humanities Communication, King's College, 2002), 35-40 (pp. 37, 40).

I7 Terry Belanger, "Meditations by the Captain of the Iceberg," in The Book Encompassed: Studies in Twentieth-Century Bibliography, ed. Peter Davison (Cambridge: Cambridge University Press, 1992), 302-9 (p. 308).

I8 University of Virginia Library, "Balanced Scorecard at UVa Library," http:// www.lib.virginia.edu/bsc/metrics/allo607.html (accessed I8 June 2007). 
been acquired are not, either because an electronic form of that work is purchased or rented instead or because the title is not obtained at all. Many books produced in recent times therefore will be among the scarcest for bibliographers to find. Meanwhile, with the text of back numbers of periodicals increasingly digitized, one fears that the long runs of print copies on library shelves will be the next category of artifactual evidence to disappear.

Such scenarios feed the gloom that Robin Alston felt when he spoke to this group on "Bibliography in the Computer Age." In 1992 Alston was not sure that computers were about to usher in a new Renaissance: "The progressive automation of libraries in Europe and North America," he said, "is based upon the belief that somehow computers will make the administration of libraries easier, widen the horizons of knowledge, assist scholarship, and benevolently lead us from darkness to light. It is, of course, as fatuous a dream as ever entered the head of a Laputian professor" (I86). (His assessment incidentally shows the difficulty of predicting the future accurately.) Computers have created problems, not least of which are the enormous financial expenditures that Alston worried about, and they pose hindrances of the kinds I have just mentioned. But they also have great capacity, hitherto largely unrealized, to aid the work of bibliographical analysis, whether by helping with existing tasks, enabling new investigation, or providing the opportunity for - indeed requiring - new analysis themselves.

A special virtue of computers is their capacity for large and humanly tedious projects. To the extent that computers can deal easily with massive amounts of data, they encourage the compilation of such troves by bibliographers. Charlton Hinman's pre-computer investigation of the Shakespeare First Folio shows that the most important component of any analysis is the mind of an imaginative researcher, but the vastness of the evidence he mustered - about spelling patterns, for instance - is daunting to those who would emulate his work. ${ }^{19}$ In an era later than Hinman's, however, computers can sort properly encoded texts with ease, and the liberation from such time-consuming drudgery can make the undertaking more feasible. A recent University of Virginia dissertator found this to be true in

I9 Hinman draws together the results of his analyses in his two-volume study The Printing and Proof-Reading of the First Folio of Shakespeare (Oxford: Clarendon Press, 1963). 
his preparation of an edition of the first publication of Uncle Tom's Cabin, in the newspaper The National Era. ${ }^{20}$ By faithfully reporting in his electronic transcription the spacing of contractions, Wesley Raabe provided a way of doing for nineteenth-century workers what Hinman had done for people more than three centuries earlier: to identify the habits of individual human beings in the printing shop.

Such machines also are good at correlating discrete sets of evidence of the same phenomenon. For bibliographers, this can involve the pooling of independent findings from different projects. Such consolidation would be particularly serviceable to the work of analytical bibliographers, whose discoveries tend to be expressed in focused reports rather than in the broader accounts of descriptive bibliography. To the extent that such discoveries - observations about the characteristics of paper in a certain period, for example - can be brought together, we will have a better basis for our generalizations about printed matter. Those tentative conclusions in turn will provide a standard against which to assess whether, for instance, the practices in a given book are typical of its era and whether its contemporary audiences would thereby be encountering something familiar, or whether the features were in some way idiosyncratic and therefore might have caught the special attention of readers.

Computers also have the capacity to correlate different kinds of evidence. Seldom is a single feature of a printed object meaningful in isolation, but the integration of multiple characteristics can require a perspicuity beyond the easy reach of the analysts. A computer, on the other hand, can be used to combine discoveries about the work of compositors (such as the fonts and even individual pieces of type they used, their treatment of punctuation, spacing, spelling, forms of contractions, speech prefixes, scene headings, stage directions, and so on) with decisions of pressmen (such as the side of each sheet they chose to print first, their setting of the points holding the paper on the press, their use of press figures, and their re-use of running titles) and with other elements of the book, such as the paper varieties the computer can be used to correlate all these findings or to adjust their combinations at will to suggest patterns for the researcher to contemplate and assess.

Imaginative thinking applied to methods of bibliographical analysis might also produce more efficient ways of accomplishing old

20 Wesley Raabe, "Harriet Beecher Stowe's Uncle Tom's Cabin: An Edition of the National Era Version" (PhD diss., University of Virginia, 2006). 
tasks. Distinguishing varieties of laid paper by tallying the pattern of spaces between chain lines has proven to be an especially useful technique, one that R. Carter Hailey, for instance, has used with considerable success first in his examination of the earliest printed editions of Piers Plowman in 1550 and more recently in his study of other English Renaissance books, including the Shakespeare quartos. ${ }^{2 \mathrm{I}}$ But processing these measurements and grouping similar ones is extremely time-consuming; computers ought to be able to do much of the sorting - and thereby entice researchers by eliminating such drudgery. Beyond that, if a computer can scan bar codes, why could it not scan chain lines and wire lines in paper, and then provide a record of what has been gleaned? Or given the advanced state of pattern recognition in other fields, why could not computers readily identify type faces? Or why could there not be an easy way of aligning two electronic images and obtaining a computer-generated account of the differences that this collation might reveal? An example of how digital technology can serve analysis comes from the work of Paul Needham and Blaise Agüera y Arcas: their electronic superimposition of high-resolution images of different instances of an alphabetical letter from early incunabula and the discrepancies thereby revealed have led these researchers to a new hypothesis about how the types were actually produced. ${ }^{22}$

Perhaps the nearest that computers now come to enabling bibliographical investigation that could not be conducted earlier is in carrying out analysis on a new, wider scale. It is difficult to draw a precise line between old tasks carried out in new ways and tasks that themselves are fundamentally new. To generate a concordance of the Bible in a fraction of a second by means of appropriate key strokes (after, of course, the program to do so has been developed and the text of the book entered into a computer) is from one point of view simply to accomplish more quickly what it took Alexander Cruden years to do. But some tasks that for a long time have been possible

2I This method of paper analysis lies behind the observations in note 25 (492-3) of Hailey's “'Geuyng light to the Reader': Robert Crowley's Editions of 'Piers Plowman' (1550)," Papers of the Bibliographical Society of America 95, no. 4 (2001): 483-502. He also applies it in "The Shakespeare Pavier Quartos Revisited," Studies in Bibliography 57 (2005-2006).

22 Agüera y Arcas describes the technique and proposes some implications in "Temporary Matrices and Elemental Punches in Gutenberg's DK Type," in Incunabula and Their Readers: Printing, Selling and Using Books in the Fifteenth Century, ed. Kristian Jensen (London: British Library, 2003), I-I2. 
have only recently become practicable as well. Though I believe it is crucial to recognize the continuity with what has happened before and to avoid self-aggrandizing claims about changes, I nonetheless think that something new is also taking place. The Early English Booktrade Database, under the direction of David Gants at the University of New Brunswick, typifies such developments. ${ }^{23}$ That project is based on the direct examination of the nearly 28,000 publications listed in the STC - the Short Title Catalogue of Books Printed in England, Scotland, and Ireland, and of English Books Printed Abroad, 1475-1640. The information collected includes collation formulas and the number of sheets in each book, the amount of type employed, the face and body of the types in each volume, the size and quality of paper used, design features, a record of the preliminary sections, and all relevant personal names. Those categories are familiar ones, and indeed the project is self-consciously a development and expansion of the work of previous researchers. It differs from earlier undertakings, however, in being designed for use on a computer. The sheer comprehensiveness would in any event make a printed publication unwieldy and unmanageable, but the main reason for the electronic medium is to enable the huge amounts of information it contains to be connected and analyzed in as many ways as an inquirer can think of asking. It is also part of still a larger network, for it will have links to other electronic databases, namely the British Book Trade Index and the English Short Title Catalogue, and thereby allow users to have ready access to biographical information or, say, to a record of extant copies. One can conceive of many of these capabilities in a printed source, but the exponential increase in the ease with which they can be realized indicates that something significantly new is occurring.

Computers have indeed become a fact of modern life, and because they are used to produce texts, they are not only tools of bibliographical investigation but also objects of analysis themselves. Despite the fact that bibliography most often is thought to concern the study of books in particular, the constitution of the Bibliographical Society of Canada remains true to its core commitment to bibliography when it says that the overall goal of the Society is "the scholarly

23 A description of the project is available online: David L. Gants, "The Early English Booktrade Database," University of New Brunswick Libraries, http:// www.lib.unb.ca/Texts/Gants/EEBD/ (accessed I8 June 2007). 
study of the history, description, and transmission of texts in all media and formats." As both W. W. Greg and Fredson Bowers point out, bibliography is characterized by a way of thinking rather than by the object of its attention. "What I am concerned with," says Greg, "is a system of investigation and a method of description, and if, with minor modifications, it can be made to apply to clay cylinders and rolls of papyrus as well as to codices of vellum or paper [or, one might add, to the physical entities we call electronic texts], so much the better." ${ }^{24}$ Bowers in turn devotes an entire essay, The Bibliographical Way, to emphasizing that "The bibliographical way is not only a technical manner of dealing with complex material. It is a logical method of analysis that inevitably prefers physical facts to immaterial speculations, but it is quite prepared to combine with any other form of criticism in whatever proportion is needed to solve the problem at hand." 25

Although the way in which a computer generates visible language differs from previous methods, the principles governing the analysis remain the same. A fundamental one is that the artifacts that result, rather than statements about the artifacts, provide the primary evidence for the history of those artifacts. Carl Spadoni employs that principle when, for instance, he analyzes the bibliographical situation and observes about an edition of Leacock's Sunshine Sketches of a Little Town that "Although this edition [item Arrf] is cited on the copyright page as a reprint of the 1933 cheap edition, it is in fact a new setting of type and the 1933 cheap edition is a reprint of Arra." ${ }^{\text {26 }}$ Robin Alston makes the point about needing to rely on the physical features of the books themselves in a slightly different way. He laments that, amid the many technological developments of the past half century, we seldom have reports within books about their production and that we must look at the physical characteristics of the actual books (as, indeed, we would have to do even if we had such statements). He attributes the absence of such accounts in part

24 W. W. Greg, "What Is Bibliography?" Transactions of the Bibliographical Society I2 (19II-13): 39-53 (p. 42); reprinted in his Collected Papers, ed. J. C. Maxwell (Oxford: Clarendon, 1966), 75-88, and in Sir Walter Greg: A Collection of His Writings, ed. Joseph Rosenblum (Lanham, MD: Scarecrow, 1998), 85-96.

25 Fredson Bowers, The Bibliographical Way (Lawrence, KS: University of Kansas Libraries, 1959), 34; reprinted in his Essays in Bibliography, Text, and Editing (Charlottesville, VA: University Press of Virginia for the Bibliographical Society of the University of Virginia, 1975), 54-74.

Spadoni, A Bibliography of Stephen Leacock, 126, entry Aurf. 
to pressures exerted by unionized labour: British publishers, he says, did not wish to incite "the National Graphical Association, which had, and was willing to exercise, the power to 'black' work from companies too eager to embrace the evolving technology of electronic typesetting." 27 With his example he incidentally emphasizes that the introduction of computer technology was not so much a break with the past as a continuation of it: anxiety in the printing trades about losing work has informed practices in recent times just as it promoted limitations on the number of copies of an edition in the early seventeenth century and provoked uproar about the introduction of Linotype and Monotype around the beginning of the twentieth century. Alston also provides an example of how problems in textual transmission remain the same regardless of the technology involved. He tells of Cambridge University Press sending a computer tape of a D. H. Lawrence novel to the publisher Granada for republication in a cheap format but failing to incorporate into it the last-minute corrections made at Cambridge. (The differences, he says, "can only be accounted for by the circumstances of the manner in which the two editions were produced." ${ }^{28}$ ) The situation he describes, of course, is generically similar to the one in which successive typescripts were confused, or in which an original typescript and its carbon copy were marked differently.

Whereas the principles of bibliographical analysis - and the need for clear thinking - remain the same no matter what the technology, computers, like all earlier forms of equipment, have unique features that analytical bibliographers must know about in order to understand what they are seeing. That truism points to a great desideratum in modern scholarship: a new Gaskell - that is, an account like Philip Gaskell's New Introduction to Bibliography that covers developments in the printing world in the second half of the twentieth century. As Alston points out, Gaskell (whose book was first published in 1972) maintains a "dignified silence" on events after $1950 .{ }^{29}$ His volume ends without covering offset printing, phototypesetting, photocopying, or computer-generated texts. I was recently reminded of the increasing complexity in one of the many areas of book production, that of typefaces, when we were forced to look for a new font for Studies

27 Alston, "Bibliography in the Computer Age," I83.

28 This concluding statement in Alston's example appears only in the version of his talk printed in The Book Encompassed, 281.

29 Alston, "Bibliography in the Computer Age," I82. 
in Bibliography. The latest volume (56) of that annual journal is the last one to be produced by Linotype, and it is possibly the last commercially produced Linotype book in America. We want to match the type reasonably well in the next volume but have quickly been reminded that simply asking for Baskerville opens a wide menu of possibilities, many of which bear little resemblance to our Linotype font. Type is only one of the categories for which analytical bibliographers will benefit from new guides. For it indeed is the case that books produced by newer technologies are as susceptible as older ones to successful bibliographical analysis. In his talk here fifteen years ago, Alston provided several examples of such interpretation, each rooted in his understanding of historical context and his awareness of the results of manufacturing processes. Speaking of a 1978 book that was reprinted in 1987 , he said:

The 1987 reprint is, on the evidence of the eye, an offset replica, though on better paper than the first edition. But how was the 1978 edition produced? Both editions, incidentally, are perfect-bound on unwatermarked paper. I suspect film-setting, for no other reason than the placement of the punctuation and the inflexible letter-spacing. (182)

In another case, he attributed the fact that "the page number on page 2I has slipped to the position which would have been occupied by the running-title" (I9In) to an error that "could only have occurred" (I83) on certain equipment (which he specified in detail). Alston also pointed out that despite apparent statements to the contrary in the first English and the first American printings of Salman Rushdie's The Satanic Verses,

Except for preliminaries and divisional titles, they are identical. No equipment currently available can, from a magnetic source, in different countries, produce pages which will pass the test of photographic super-imposition. Yet sample pages put to this test reveal not the slightest difference. It must be assumed that production of both editions took place in one production unit. ${ }^{30}$

Printed materials produced by computer can also provide insight into the history of their manufacture. For some reason documents associated with American presidents seem to have attracted this kind of scrutiny. One of the best known examples, from the days before

30 Quoted from The Book Encompassed, 282, which inserts the final two sentences. 
computers, was William Todd's analysis of the transcriptions of President Nixon's Watergate tapes. ${ }^{3 \mathrm{I}}$ Using techniques familiar to students of Shakespeare's First Folio, Todd was able to identify the various typists, only one of whom consistently spelled "all right" all right.

But more recent holders of the office have also spurred bibliographical analysis. When independent prosecutor Kenneth Starr's report on President Clinton's relationship with Monica Lewinsky was first released, its footnotes were filled with errors. The problem arose when the report, which had been prepared in WordPerfect, was converted to hypertext markup language (or HTML), a form used on the Internet. According to an account in the Washington Post,

The report suddenly sprouted footnotes that previously had been trimmed by Starr's prosecutors and dropped some words intended for publication. In some cases, footnote numbers were removed from the main text where they belonged.

Here's one type of glitch that cropped up: When one edits out footnoted material in WordPerfect, the document inserts an invisible symbol into the text that says, in effect, ignore the following passage. But the conversion to HTML had the effect of inserting a countermanding symbol: Ignore the ignore command. ${ }^{32}$

Again, knowing how to interpret the physical evidence is part of knowing how to interpret the utterance itself.

Bibliographical analysis has also accompanied the current president. When two years ago a letter surfaced about President Bush's military service or lack thereof, I was surprised to find that I could produce a close facsimile of it in Microsoft Word. (I know the facsimile was close, because I collated it on a Hinman Collator.) What I also discovered was that anomalous spacing in it could be explained by the use of Word's standard tab settings instead of the expected space bar. It didn't require my examination to establish that the letter was suspect, but one of the tests by which the letter eventually came to be dismissed was through the bibliographical analysis of the type font,

3I William B. Todd, "The White House Transcripts," Papers of the Bibliographical Society of America 68, no. 3 (1974): 267-96.

32 John Mintz and Nathan Abse, "Glitches Altered Version of Starr Report Online, in Post," Washington Post (16 September 1998), A34. 
which was inconsistent with the date of the document's purported origin. ${ }^{33}$

My last example of the bibliographical analysis of texts produced by computers comes from David Greetham's book Textual Scholarship: An Introduction. Greetham cites a strange misprint in this sentence from the New York Times: "the loss of . . . [Ukraine's] 52 million Slavs would tilt the ethnic balance of the remaining union toward the Muslim oslems of Central Asia". ${ }^{34}$ As Greetham explains things,

These mysterious "oslems" were presumably created when a Times stylist noticed the form "Moslems" (rather than the preferred Times style "Muslims"), but instead of striking out the entire word left the initial " $M$ " in place and inserted "uslims," without, however, remembering to delete the offending "oslems." The sequence of error would be impossible in a non-electronic medium. (29I)

Greetham's example incidentally illustrates the intimate relationship among what are sometimes considered three separate fields of intellectual inquiry. The problem that arises is textual: the wording doesn't make sense. The ramifications of this text (that is, of the way of referring to a group of people) are social - and thus in the realm of what is typically referred to as book history. The explanation of the problem is bibliographical, achieved by an interpretation of the physical evidence in light of an awareness about the possible means of production. Greetham's little illustration thus has the added benefit of demonstrating in a nutshell how these approaches might wisely be seen as part of a continuum rather than as three separate fields.

Returning to the question that has prompted this session, what indeed are the prospects for bibliographical analysis? That future is very bright, I would say: because the opportunities are unbounded, because analysis can accomplish so much in terms of understanding our world, because new tools are available, and because these tools themselves serve as new objects of study. As bibliographical analysis

33 For an image of the letter (of 4 May 1972), one of several questioned documents in the controversy, see: "Bush Guard Memos Questioned: CBS News Stands By Story About Lapses In His Nat'l Guard Record," CBS News, Io September 2004, http://www.cbsnews.com/htdocs/pdf/BushGuardmay4.pdf available at http:// www.cbsnews.com/stories/2004/09/ro/politics/main642729.shtml (accessed I8 June 2007).

34 D. C. Greetham, Textual Scholarship: An Introduction (New York: Garland, 1992), 290. 
advances, it will certainly benefit from the capabilities that computers provide. But these means, like all others, will prove beneficial only to the extent that the people employing them apply careful judgement in framing the applications and interpreting the results.

How will awareness of the method and value of this approach to understanding be spread? Through explicit teaching and through the provision of models, to begin with. Perhaps enlightened educational institutions will accommodate the formal instruction, but teaching might have to come from people who in the course of their other duties illustrate the methods and value of interpreting the physical world and demonstrating how through it we can meet the past. It is the case with the American Council of Learned Societies, and I think to some extent with the Canadian Federation for the Humanities and Social Sciences as well, that the fields of many member organizations are not often represented in the academy. One implication is that these societies themselves must assume the role of perpetuating what they stand for - and of thinking of ways to do so. The anticipated resumption of the Canadian Institute of Analytical Bibliography provides a welcome example of how bibliographical education might be advanced outside of formal academic structures.

Whatever the circumstances, it will be important to proceed with an understanding of the role of the physical in human activity and the role of physical evidence in revealing the past and understanding the present. It will also be crucial to recognize that the study of books and other artifacts is ultimately the study of human actions. It is especially in this way that bibliography is, in the words of our conference title, "beyond the text."

The announcement for our present conference suggests that the field of bibliography has broadened in recent decades from a concern with the physical to an interest in the sociological. While acknowledging that a change has occurred, I would suggest thinking of it instead as a shift of emphasis and seeing both the earlier focus on the physical characteristics of books and the current one on their role in society as components of a larger whole. Without both of them, that totality is narrowed.

\section{SOMMAIRE}

Quel est l'avenir de la bibliographie analytique à "l'ère des ordinateurs»? Même sans l'existence de ces derniers, les perspectives 
d'apprentissage concernant l'histoire des livres à partir de leurs caractéristiques physiques s'avèrent toujours prometteuses. Le nombre presque illimité de livres à examiner, la richesse insoupçonnée des procédés de composition et d'impression qui restent encore à découvrir et l'analyse des particularités techniques qui suscitent depuis peu l'attention des créateurs et des utilisateurs, voilà autant d'éléments qui justifient une approche nouvelle et excitante. Même si l'apparition des ordinateurs a compromis dans un certain sens la conservation des livres existants, leur présence fournit déjà une impulsion nouvelle à l'analyse bibliographique. Les ordinateurs s'accommodent bien aux projets d'envergure qui rebutent les humains, ils établissent une corrélation adéquate avec des situations spécifiques aussi bien que particulières et ils élaborent des moyens utiles et novateurs dans la poursuite des méthodes antérieures de recherche. Étant donné que ces outils génèrent du texte, ils deviennent eux-mêmes des objets d'analyse selon les mêmes principes régissant l'investigation bibliographique. Tout en reconnaissant l'utilité de l'étude des artéfacts dans la compréhension du passé et des nouveaux outils maintenant disponibles dans la réalisation d'un tel travail, les experts en bibliographie analytique vivent à l'heure actuelle un moment déterminant. 